\title{
Mass Spectral Study on O,O-Dialkyl N,N- Dialkyl Phosphoramidates Under Electron Impact Conditions
}

\author{
T. Jagadeshwar Reddy, S. Prabhakar, U.V.R. Vijaya Saradhi, \\ V. Jayathirtha Rao, and M. Vairamani \\ National Center for Mass Spectrometry, Indian Institute of Chemical Technology, Hyderabad, India
}

\begin{abstract}
A series of O,O-dialkyl N,N-dialkyl phosphoramidates (1-25) were analyzed under GC-EIMS conditions. Clear-cut differences are found in the fragmentation of $\mathrm{O}, \mathrm{O}-$ dialkyl $\mathrm{N}, \mathrm{N}$-dimethyl phosphoramidates (Series 1) and O,O-dimethyl N,N-dialkyl phosphoramidates (Series 2). The phosphoramidates comprising of mixed/crossed alkyl groups on nitrogen and oxygen (Series 3) showed mixed fragmentation pattern corresponding to both Series 1 and 2 depending on the nature of alkyl groups. All the possible isomers among the studied compounds showed distinguishable EI mass spectra. Although the major ions in the EI mass spectra for the isomers containing O-n-propyl or O-isopropyl and N,N-diethyl or N-isopropyl N-methyl are similar, the isomers could be distinguished by characteristic ions of low abundance at low mass region. The differences are prominent in the metastable ion spectra of characteristic ions. (J Am Soc Mass Spectrom 2004, 15, 547-557) (C 2004 American Society for Mass Spectrometry
\end{abstract}

$\mathrm{T}$ The organophosphonates and phosphoramidates are some of the toxic substances that are commonly used as pesticides and chemical warfare agents (CWA). In view of major concerns regarding the toxicity of these compounds and alleged use of the CWA [1], there is a need for the development of innovative analytical methods for specific detection and identification of these compounds in different environmental and biological matrices at trace levels. Number of methods are reported in the literature regarding the analysis of chemical warfare agents by mass spectral techniques and gas chromatographic techniques with element-specific detectors such as NPD, FPD etc. [2-14]. Electron impact (EI) ionization is extensively used for the verification of many chemical warfare agents because of its high sensitivity. The EI mass spectra of many chemical warfare agents and their degradation products are available in the data base compiled by the Organization for the Prohibition of Chemical Weapons (OPCW), The Netherlands, and in other commercial library databases. Capillary column gas chromatographs equipped with mass selective detectors (GC/ MSD) in EI and chemical ionization (CI) modes are widely used for the unambiguous identification of compounds present in different environmental matrices [2-14]. Recently, we reported the mass spectral analysis of $\mathrm{N}, \mathrm{N}$-dialkyl aminoethanols that are precursors for

Published online February 6, 2004

Address reprint requests to Dr. M. Vairamani, National Center for Mass Spectrometry, Indian Institute of Chemical Technology, Hyderabad 500007, India. E-mail: vairamani@iict.res.in

various nitrogen mustards and nerve agents (VX) [15]. The EI mass spectra of diethyl and dimethyl N,Nmethylphosphoramidates are reported in literature $[3$, $10]$ and the EI mass spectra for some of the phosphoramidates are available in the OPCW and other commercial mass spectral library databases. However, to the best of our knowledge, no detailed investigation on the mass spectral fragmentation of these compounds is available in the literature. Herein we report the results of a detailed study on the EI mass spectral behavior of twenty-five phosphoramidates. The study is also focused on the differentiation of isomeric compounds.

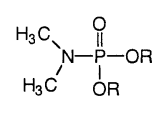

Series 1

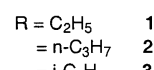

$\begin{array}{ll}=\mathrm{i}-\mathrm{C}_{3} \mathrm{H}_{7} & 3 \\ =\mathrm{n}-\mathrm{C}_{4} \mathrm{H}_{9} & 4\end{array}$

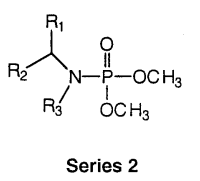

$R_{1}=R_{2}=H, \quad R_{3}=\mathrm{CH}_{3}$

$\mathrm{R}_{1}=\mathrm{CH}_{3}, \quad \mathrm{R}_{2}=\mathrm{H}, \quad \mathrm{R}_{3}=\mathrm{C}_{2} \mathrm{H}_{5}$ $R_{1}=C_{2} H_{5}, R_{2}=H_{1}, R_{3}=C_{3}$ $R_{1}=R_{2}=R_{3}=C_{3}$ $R_{1}=C_{2} H_{5}, R_{2}=H, \quad R_{3}=C_{3} H_{7}$

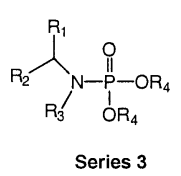

$R_{1}=\mathrm{CH}_{3}, \mathrm{R}_{2}=\mathrm{H}, \mathrm{R}_{3}=\mathrm{C}_{2} \mathrm{H}_{5}, \mathrm{R}_{4}=\mathrm{C}_{2} \mathrm{H}_{5}$ $\mathrm{R}_{1}=\mathrm{CH}_{3}, \mathrm{R}_{2}=\mathrm{H}, \mathrm{R}_{3}=\mathrm{C}_{2} \mathrm{H}_{5}, \mathrm{R}_{4}=\mathrm{n}-\mathrm{C}_{3} \mathrm{H}_{7}$ $R_{1}=C_{3}, R_{2}=H, R_{3}=C_{2} H_{5}, R_{4}=i-C_{3} H_{7}$ $R_{1}=C_{3}, R_{2}=H, R_{3}=C_{2} H_{5}, R_{4}=i-C_{3} H_{7}$
$R_{1}=C_{3}, R_{2}=H, R_{3}=C_{2} H_{5}, R_{4}=n-C_{4} H_{9}$ $\mathrm{R}_{1}=\mathrm{C}_{2} \mathrm{H}_{5}, \mathrm{R}_{2}=\mathrm{H}, \mathrm{R}_{3}=\mathrm{CH}_{3}, \mathrm{R}_{4}=\mathrm{C}_{2} \mathrm{H}_{5}$ $R_{1}=C_{2} H_{5}, R_{2}=H, \quad R_{3}=C_{3}, R_{4}=n-C_{3} H_{7}$ $R_{1}=C_{2} H_{5}, R_{2}=H, R_{3}=C_{3}, R_{4}=i-C_{3} H_{7}$ $\mathrm{R}_{1}=\mathrm{C}_{2} \mathrm{H}_{5}, \mathrm{R}_{2}=\mathrm{H}, \mathrm{R}_{3}=\mathrm{CH}_{3}, \mathrm{R}_{4}=\mathrm{n}-\mathrm{C}_{4} \mathrm{H}_{9}$

$R_{1}=R_{2}=R_{3}=C_{3}, R_{4}=C_{2} H_{5}$ $R_{1}=R_{2}=R_{3}=C_{3}, R_{4}=n-C_{3} H_{7}$ $R_{1}=R_{2}=R_{3}=C_{3}, R_{4}=i-C_{3} H_{7}$ $R_{1}=R_{2}=R_{3}=C_{3}, R_{4}=n-C_{4} H_{9}$ $R_{1}=C_{2} H_{5}, R_{2}=H, R_{3}=n-C_{3} H_{7}, R_{4}=n-C_{3} H_{7} 23$ $\mathrm{R}_{1}=\mathrm{C}_{2} \mathrm{H}_{5}, \mathrm{R}_{2}=\mathrm{H}, \mathrm{R}_{3}=\mathrm{n}-\mathrm{C}_{3} \mathrm{H}_{7}, \mathrm{R}_{4}=\mathrm{i}-\mathrm{C}_{3} \mathrm{H}_{7} \quad 24$ $\mathrm{R}_{1}=\mathrm{C}_{2} \mathrm{H}_{5}, \mathrm{R}_{2}=\mathrm{H}, \mathrm{R}_{3}=\mathrm{n}-\mathrm{C}_{3} \mathrm{H}_{7}, \mathrm{R}_{4}=\mathrm{n}-\mathrm{C}_{4} \mathrm{H}_{9} 25$ 
Table 1. Partial EI mass spectra of Series-1 compounds ${ }^{\mathrm{a}}$

\begin{tabular}{|c|c|c|c|c|c|c|c|c|c|c|c|}
\hline \multirow{2}{*}{$\begin{array}{l}\text { Comp } \\
\text { no. }\end{array}$} & \multicolumn{11}{|c|}{ lon, $m / z$ (relative abundance $\%$ ) } \\
\hline & $\mathrm{M}^{+}$ & $\mathbf{a}$ & b & c & d & e & $\mathbf{f}$ & g & $\mathbf{h}$ & $\mathbf{i}$ & Other ions \\
\hline 1 & $181(13)$ & $44(100)$ & $136(4)$ & $108(20)$ & $153(5)$ & - & - & - & $152(4)$ & $124(26)$ & $\begin{array}{l}138(3), 110(7), 82(6) \\
81(4), 65(2), 43(10) \\
42(14)\end{array}$ \\
\hline 2 & $209(2)$ & $44(100)$ & $150(5)$ & $108(36)$ & $167(1)$ & $125(10)$ & $168(23)$ & $126(75)$ & $166(2)$ & $124(30)$ & $\begin{array}{l}110(5), 83(5), 82(3), \\
45(12), 43(17), \\
42(12), 41(11)\end{array}$ \\
\hline 3 & $209(8)$ & $44(100)$ & $150(9)$ & $108(27)$ & $167(4)$ & $125(55)$ & $168(4)$ & $126(16)$ & $166(3)$ & $124(22)$ & $\begin{array}{l}152(5), 110(3), 59(3) \\
45(10), 43(20), \\
42(11), 41(9)\end{array}$ \\
\hline 4 & $237(1)$ & $44(49)$ & $164(2)$ & $108(26)$ & $181(<1)$ & $125(9)$ & $182(21)$ & $126(100)$ & $180(1)$ & $124(16)$ & $\begin{array}{l}152(2), 110(3), 83(3) \\
57(3), 45(6), 43(5), \\
42(6), 41(9)\end{array}$ \\
\hline
\end{tabular}

${ }^{\mathrm{a}}$ The contribution from isotopic peaks are not subtracted.

\section{Experimental}

\section{Materials}

All phosphoramidates used in the present study were synthesized in-house by reported methods [16-18]. The compounds were characterized by infrared and ${ }^{1} \mathrm{H}$ nuclear magnetic resonance spectroscopy. Chemicals and solvents used for the synthesis were purchased from Sd-Fine Chemicals (Mumbai, India). Analytical grade solvents for chromatographic and mass spectrometric analysis were obtained from E-Merck (Mumbai, India).

\section{Mass Spectral Analysis}

The GC-MS analyses were performed using an Agilent 6890 GC (Agilent Technologies, Palo Alto, CA) equipped with a model $5973 \mathrm{~N}$ mass selective detector and a HP-5 MS capillary column of length $30 \mathrm{~m}, 250 \mu \mathrm{m}$ i.d. and $0.25 \mu \mathrm{m}$ film thickness, was used. The column oven was programmed initially from $50{ }^{\circ} \mathrm{C}$ with $2 \mathrm{~min}$ hold up time to the final temperature of $280{ }^{\circ} \mathrm{C}$ with 10 ${ }^{\circ} \mathrm{C} / \mathrm{min}$ ramp. The final temperature hold-up time was
3 min. Helium was used as carrier gas in constant flow mode at a flow rate of $1.2 \mathrm{ml} / \mathrm{min}$. The inlet and GC/MS interface temperatures were kept at $280{ }^{\circ} \mathrm{C}$. The samples were introduced in splitless injection mode. The temperatures of the EI source and quadrupole analyzer were kept at $230{ }^{\circ} \mathrm{C}$ and $150{ }^{\circ} \mathrm{C}$, respectively. The MS was scanned from $\mathrm{m} / \mathrm{z} 20$ to 600 for all GC-MS experiments.

Collision induced dissociation (CID) spectra were recorded using a VG Autospec mass spectrometer (Manchester, UK) equipped with an OPUS V3.IX data system, using a dedicated EI source. The source conditions for electron impact were: Accelerating voltage 7 $\mathrm{kV}$, electron energy $70 \mathrm{eV}$, trap current $200 \mu \mathrm{A}$ and source temperature $250^{\circ} \mathrm{C}$. Spectra were acquired using the data system with a scan time of $3 \mathrm{~s} /$ decade and $0.5 \mathrm{~s}$ interscan delay. All the samples are introduced through a septum reservoir inlet at $200{ }^{\circ} \mathrm{C}$. CID fragment ion spectra were measured using the linked scan technique at constant B/E under computer control, with helium as the collision gas admitted into the first field-free region so that the main beam transmission was reduced to $20-30 \%$ of its original intensity. Parent-ion spectra were

Table 2. Partial EI mass spectra of Series-2 compounds ${ }^{\mathrm{a}}$

\begin{tabular}{|c|c|c|c|c|c|c|c|c|c|c|c|}
\hline \multirow{2}{*}{$\begin{array}{l}\text { Comp } \\
\text { no. }\end{array}$} & \multicolumn{11}{|c|}{ lon, $m / z$ (relative abundance $\%$ ) } \\
\hline & $\mathrm{M}^{+}$ & $\mathbf{j}$ & $\mathbf{k}$ & I & $\mathbf{m}$ & $\mathbf{n}$ & $\mathbf{0}$ & $\mathbf{p}$ & $\mathbf{q}$ & $\mathbf{r}$ & Other ions \\
\hline 5 & $153(23)$ & $44(100)$ & $109(35)$ & - & - & - & - & - & $138(6)$ & $122(18)$ & $\begin{array}{r}110(10), 95(6), 80(8), \\
79(12), 43(8), 42(18)\end{array}$ \\
\hline 6 & $181(11)$ & $72(12)$ & $109(40)$ & $166(100)$ & $136(15)$ & $108(17)$ & - & $138(31)$ & $152(11)$ & $150(11)$ & $\begin{array}{r}120(5), 93(3), 79(9) \\
56(6), 44(5), 42(7)\end{array}$ \\
\hline 7 & $181(5)$ & $72(6)$ & $109(42)$ & $152(100)$ & $122(29)$ & - & - & - & $138(2)$ & $150(1)$ & $\begin{array}{l}166(1), 111(5) \\
108(3), 93(3), 79(7) \\
72(6), 42(6)\end{array}$ \\
\hline 8 & $181(2)$ & $72(8)$ & $109(24)$ & $166(100)$ & $136(3)$ & - & $134(22)$ & - & $138(2)$ & $150(3)$ & $\begin{array}{r}108(7), 93(4), 79(6) \\
72(8), 56(25), 42(7)\end{array}$ \\
\hline 9 & $209(3)$ & $100(4)$ & $109(22)$ & $180(100)$ & $150(3)$ & $108(13)$ & - & $138(48)$ & $166(4)$ & $178(<1)$ & $\begin{array}{l}152(5), 79(5), 70(3), \\
56(2), 43(5), 42(6), \\
41(6)\end{array}$ \\
\hline
\end{tabular}

aThe contribution from isotopic peaks are not subtracted. 
Table 3. Partial EI mass spectra of Series-3 compounds

\begin{tabular}{|c|c|c|c|c|c|c|c|c|c|c|c|c|c|c|c|c|c|c|c|}
\hline \multirow{2}{*}{$\begin{array}{l}\text { Comp } \\
\text { no. }\end{array}$} & \multicolumn{18}{|c|}{ Relative abundance (\%) } & \multirow{2}{*}{$\begin{array}{c}\text { Other ions } m / z \text { (relative } \\
\text { abundance) }\end{array}$} \\
\hline & $\mathrm{M}^{+}$ & $\mathbf{s}$ & $\mathbf{t}$ & $\mathbf{u}$ & $\mathbf{v}$ & $\mathbf{w}$ & $\mathbf{x}$ & y & $\mathbf{z}$ & $\mathbf{a}^{\prime}$ & $\mathbf{b}^{\prime}$ & $\mathbf{c}^{\prime}$ & $\mathbf{d}^{\prime}$ & $\mathbf{e}^{\prime}$ & $\mathbf{f}^{\prime}$ & $\mathbf{g}^{\prime}$ & $\mathbf{h}^{\prime}$ & $\mathbf{i}^{\prime}$ & \\
\hline 10 & 14 & 23 & 98 & 38 & 100 & 35 & $-^{a}$ & 11 & 9 & $-b$ & 5 & 8 & 14 & 5 & 14 & - & - & 5 & $\begin{array}{l}120(4), 92(7), 81(8), 56(7) \\
44(11), 42(9)\end{array}$ \\
\hline 13 & 4 & 18 & 52 & 26 & 100 & 15 & $<1$ & 2 & 1 & 2 & 1 & 6 & 11 & 2 & 14 & 7 & 9 & 2 & $\begin{array}{l}92(3), 80(3), 57(4), 56(4), 44(5) \\
42(3), 41(6)\end{array}$ \\
\hline 14 & 4 & 14 & 85 & 32 & 100 & - & - & 13 & 6 & - & $--^{c}$ & $-^{a}$ & - & 3 & $-d$ & - & - & - & $\begin{array}{l}94(5), 81(7), 44(20), 43(12) \\
42(19)\end{array}$ \\
\hline 15 & 2 & 8 & 47 & 22 & 100 & - & - & 1 & 2 & - & $<1$ & 3 & - & 3 & 7 & $<1$ & $<1$ & - & $\begin{array}{l}106(4), 94(4), 44(10), 43(12) \\
42(9), 41(9)\end{array}$ \\
\hline 16 & 1 & 5 & 14 & 13 & 100 & - & - & 1 & 1 & - & 1 & 4 & - & 4 & 6 & - & - & - & $\begin{array}{l}106(5), 94(3), 44(8), 43(10) \\
42(8), 41(7)\end{array}$ \\
\hline 17 & 1 & 9 & 44 & 19 & 100 & - & - & 1 & 2 & - & $<1$ & 4 & - & 1 & 5 & 1 & 2 & - & $\begin{array}{l}112(4), 94(4), 57(3), 44(8), 43(5) \\
42(6), 41(8)\end{array}$ \\
\hline 18 & 2 & 12 & 87 & 31 & 100 & - & - & 2 & 1 & - & $<1$ & 2 & - & 4 & 6 & - & - & - & $\begin{array}{l}178(1), 120(16), 110(4), 94(12) \\
81(5), 58(7), 56(14), 42(9)\end{array}$ \\
\hline 19 & 1 & 9 & 50 & 18 & 100 & - & - & 2 & 2 & - & - & 3 & - & 4 & 9 & $<1$ & 1 & - & $\begin{array}{l}120(8), 112(3), 110(3), 94(12) \\
56(9), 43(11), 42(9), 41(11)\end{array}$ \\
\hline 21 & 1 & 8 & 51 & 19 & 100 & - & - & 1 & - & - & - & 3 & - & 2 & 4 & 1 & 1 & - & $\begin{array}{l}120(7), 112(5), 110(3), 94(11) \\
56(7), 41(7)\end{array}$ \\
\hline 22 & 3 & 8 & 100 & 29 & 42 & 44 & 8 & 11 & 8 & $-d$ & $-^{c}$ & $-{ }^{a}$ & 12 & 2 & $-d$ & - & - & 1 & $\begin{array}{l}124(2), 110(44), 92(3), 81(5) \\
70(4), 58(3), 56(3), 43(7), 42(6) \\
41(8)\end{array}$ \\
\hline 23 & 2 & 8 & 90 & 34 & 100 & 41 & $-^{a}$ & 3 & 7 & 8 & 1 & 2 & 7 & 3 & $-\mathrm{e}$ & - & 1 & $-^{f}$ & $\begin{array}{l}124(4), 70(4), 58(3), 56(3) \\
43(12), 42(5), 41(11)\end{array}$ \\
\hline 24 & 1 & 3 & 19 & 15 & 100 & 23 & $-^{a}$ & 1 & 2 & 7 & $<1$ & 4 & 4 & 4 & $-\mathrm{e}$ & - & - & $-^{f}$ & $\begin{array}{l}124(2), 70(3), 58(2), 56(2) \\
43(11), 42(4), 41(8)\end{array}$ \\
\hline 25 & 2 & 8 & 93 & 28 & 100 & 35 & 1 & 2 & 5 & 4 & $<1$ & 2 & 6 & 2 & 6 & 1 & 1 & 1 & $\begin{array}{l}124(4), 70(3), 57(3), 43(5), 42(3) \\
41(10)\end{array}$ \\
\hline
\end{tabular}

Ion coincides a with ion ' $\mathbf{u}^{\prime}$, ${ }^{\mathrm{b}}$ with ' $\mathbf{z}^{\prime},{ }^{\mathrm{c}}$ with ' $\mathbf{t}^{\prime}$, d with ' $\mathbf{y}^{\prime}$, e with ' $\mathbf{a}^{\prime}$, ${ }^{\mathrm{f}}$ with ion ' $\mathbf{b}^{\prime}$.

obtained using the linked scan technique at constant $\mathrm{B}^{2} / \mathrm{E}$. Mass analyzed ion-kinetic energy (MIKE) spectra were acquired under similar conditions and the collision gas admitted into the third field-free region.

\section{Results and Discussion}

The phosphoramidates are listed as Schedule 2B chemicals of the Chemical Weapons Convention (CWC) and are also the by-products in the synthesis of nerve agent Tabun (ethyl dimethylphosphoramidocyanidate). Their presence in the environmental matrices such as soil, water, oil etc. indicates the alleged production and usage of Tabun-like compounds. These chemicals are freely soluble in organic solvents and sparingly soluble in water. They can be extracted from the matrices using polar hydrophobic solvents like $\mathrm{CH}_{2} \mathrm{Cl}_{2}, \mathrm{CHCl}_{3}$ etc., and analyzed by GC/MS using EI and CI techniques for unambiguous identification. We have analyzed twentyfive phosphoramidates under GC-EIMS conditions. The molecular structures for the studied compounds are given in Scheme 1. Most of the compounds studied were pure $(>98 \%)$ and few compounds with minor impurities (5\%) were well resolved during GC-MS analysis to provide clean EI mass spectra. The EI mass spectra of phosphoramidates show extensive fragmentation following a characteristic pathway. The knowledge on this fragmentation facilitates the identification of the structures of the chemicals. The EI mass spectral data of all phosphoramidates studied here are presented in Tables 1, 2, and 3. The EI mass spectra show the presence of molecular ions and distinguishable fragment ions for most of the phosphoramidates studied. For the convenience of discussion, the compounds analyzed are grouped into three series. The O,O-dialkyl, N,N-dimethyl phosphoramidates (1-4) are considered as Series-1, O,O-dimethyl, N,N-di-alkyl phosphoramidates (5-9) as Series-2, and O,O-dialkyl, N,Ndialkyl phoshoramidates (10-25) as Series-3.

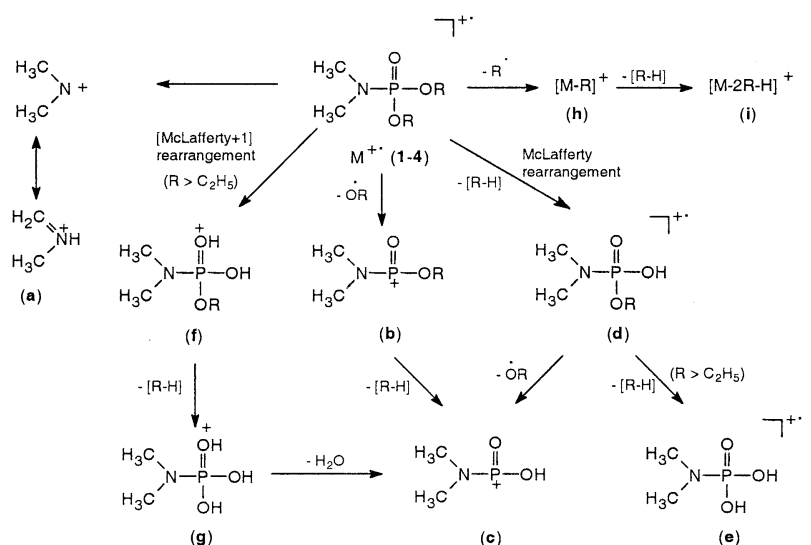

Scheme 2 


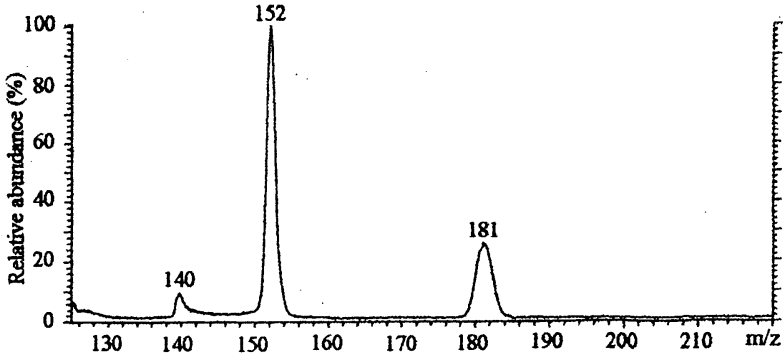

Figure 1. Parent-ion spectrum of the ion at $m / z 124$ from Compound 1 .

\section{O,O-Dialkyl N,N-Dimethyl Phosphoramidates (Series 1)}

The compounds in this series show relatively less fragmentation when compared to the other two series. The EI mass spectra for Compounds 1-4 are presented in Table 1. The EI fragmentation process in $\mathrm{O}, \mathrm{O}$, -dialkyl N,N-dimethyl phosphoramidates (1-4) is summarized in Scheme 2, as supported by metastable ion spectra. All the compounds in this series, except 4, show ion at $m / z 44$ (a) as the base peak. The ion a is diagnostic to $\mathrm{N}, \mathrm{N}$-dimethyl phosphoramidates, and resulted from the molecular ion by the simple cleavage of phosphoramide bond between $\mathrm{P}$ and $\mathrm{N}$ leaving the charge on nitrogen. The $[\mathrm{M}-\mathrm{OR}]^{+}$ion (b) and ion c $(m / z$ 108) resulting from the loss of an alkene from ion $\mathbf{b}$ are observed in all the cases. Sequential loss of alkyl radicals from molecular ion is found in the case of higher alkyl group containing compounds, and the resulting ions are of low abundance. Loss of an alkene moiety by the McLafferty rearrangement [19] process involving the alkoxy
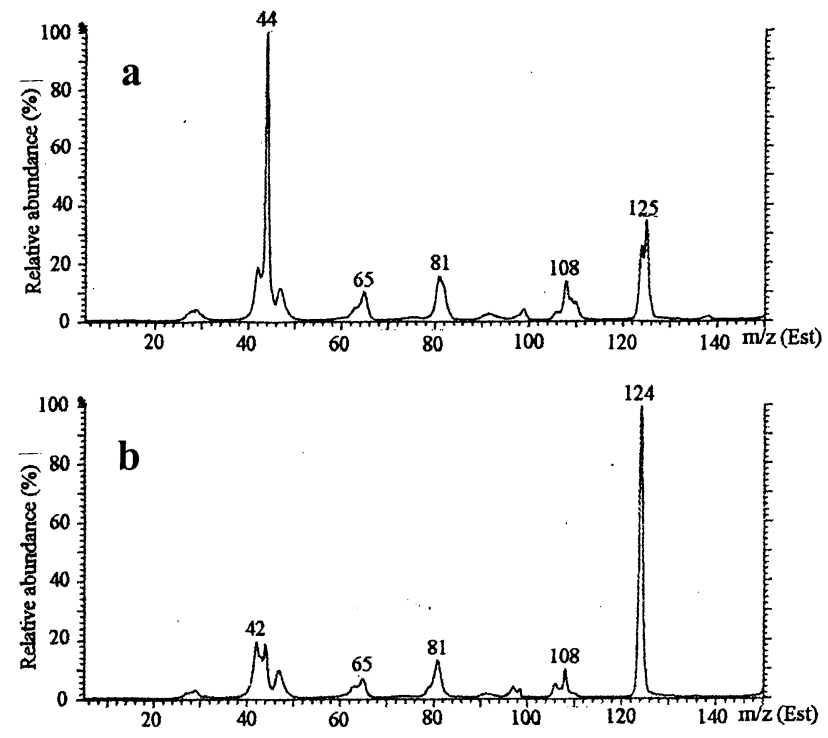

Figure 2. MIKE-CID daughter ion spectrum of (a) ion at $m / z$ 152, (b) ion at $m / z 153$ from Compound 1 .

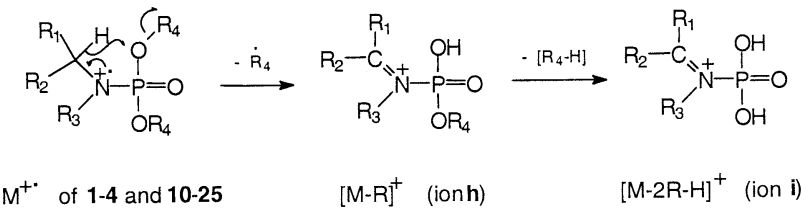

Scheme 3

group leads to prominent ion $\mathbf{d}$ in Compounds $\mathbf{1}$ and 3. The ion $\mathbf{d}$ is negligible in $\mathbf{2}$ and $\mathbf{4}$. However, loss of an alkene molecule from ion $\mathbf{d}$ leads to ion $\mathbf{e}$ in Compounds 2-4. In the case of higher alkyl group containing compounds ( 2 and 4 ), the [McLafferty +1$]$ rearrangement process [19] is prominent resulting in ion $\mathbf{f}$, and elimination of an alkene from ion $\mathbf{f}$ gives ion $\mathbf{g}$ in the spectra (base peak in 4 ). Loss of water molecule from $\mathbf{g}$ leads to ion $\mathbf{c}$.

The ion at $m / z 124$ (i) is characteristically found in all the compounds (1-4) though it is not abundant. The parent ion spectrum of ion $\mathbf{i}$ from Compound $\mathbf{1}$ shows $[\mathrm{M}-\mathrm{R}]^{+}$ion $(\mathbf{h})$ as the major precursor and the molecular ion as the other precursor (Figure 1). The formation of the ion $\mathbf{i}$ from the ion $\mathbf{h}$ is further confirmed by the MIKE-CID spectrum of ion $\mathbf{h}$ from Compound 1 wherein the loss of alkene is the dominant process (Figure 2). The possibility of formation of ion $\mathbf{i}$ from ion $\mathbf{d}$ is less favorable as reflected in the MIKE-CID spectrum of ion $\mathbf{d}$ from Compound $\mathbf{1}$ (Figure 2). The feasibility for the formation of [M $\mathrm{R}]^{+}$from the molecular ion is attributed to the initial $[1,4]$ hydrogen migration from methyl group on nitrogen to oxygen of the alkoxy group (Scheme 3 ). Such kind of radical elimination involving hydrogen migration is known in the literature [20].

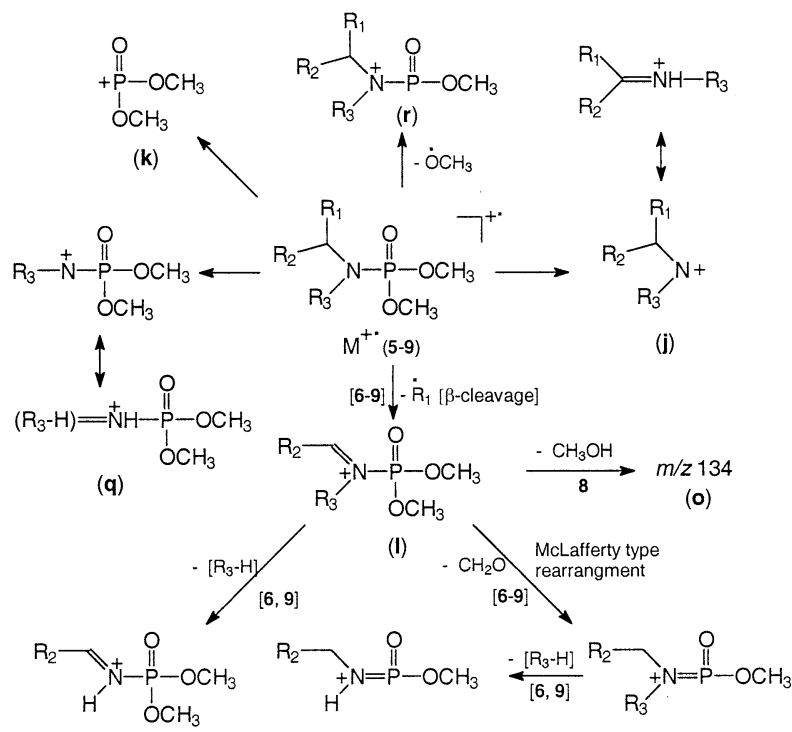

(p)

(n)

(m)

Scheme 4 


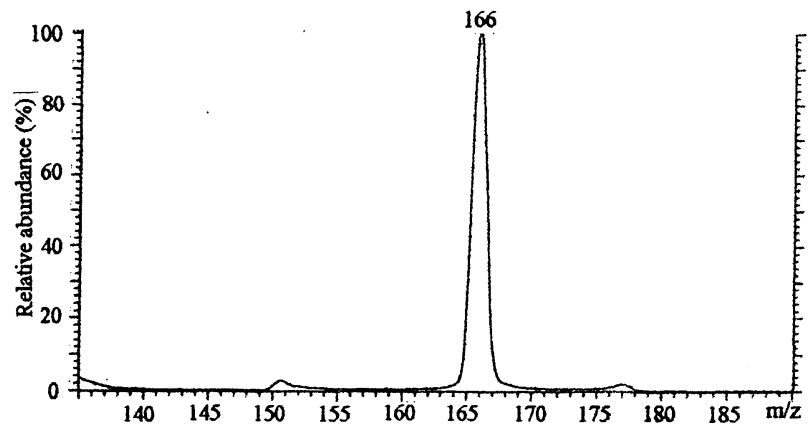

Figure 3. Parent-ion spectrum of the ion at $\mathrm{m} / \mathrm{z} 134$ from Compound 8 .

\section{O,O-Dimethyl N,N-Dialkyl Phosphoramidates}

(Series 2)

The Series 2 compounds (5-9) show fragmentation pattern (Scheme 4) different from those of the Series 1 (1-4) and 3 (10-25) compounds. The EIMS data for these compounds are presented in Table 2. The cleavage of phosphoramide bond in molecular ion is observed in all the cases, and unlike Series 1 and 3 compounds the charge is retained on both possible fragments $\mathbf{j}$ and $\mathbf{k}$. The ion $\mathbf{k}$ appearing at $\mathrm{m} / \mathrm{z} 109$ is found to be charac-

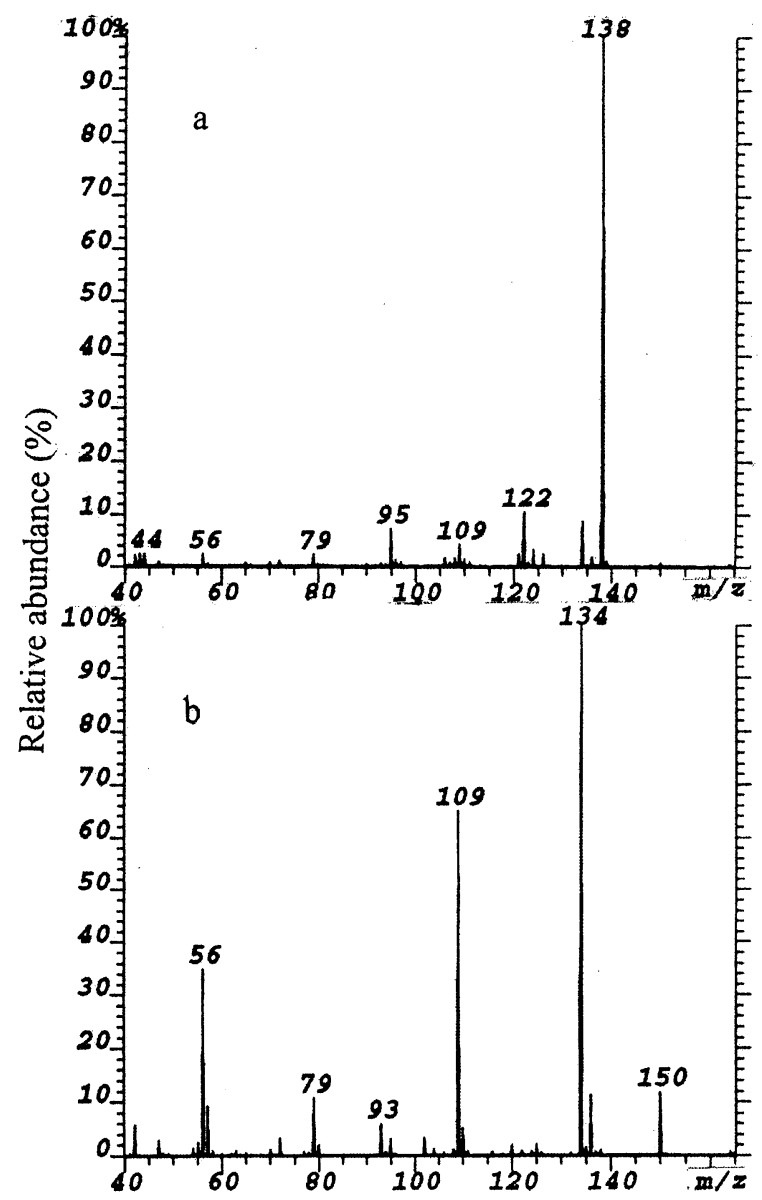

Figure 4. Daughter-ion spectra of the ion at $\mathrm{m} / \mathrm{z} 166$ from (a) Compound 7, (b) Compound 8.

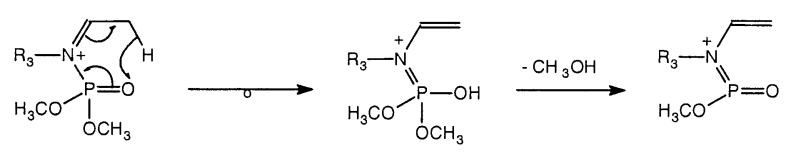

ion 1 of 8

$m / 2134 \quad$ (ion o)

Scheme 5

teristic for O,O-dimethyl phosphoramidates studied. The relative abundance of ion $\mathbf{k}$ is higher than that of ion $\mathbf{j}$, except in Compound $\mathbf{5}$ wherein the ion $\mathbf{j}$ is the base peak in the spectrum. All the compounds containing higher alkyl groups $\left[\mathrm{R}>\mathrm{CH}_{3}\right]$ on nitrogen show the $\beta$-cleavage [15] fragment ion (1) as the base peak. Further elimination of $\mathrm{CH}_{2} \mathrm{O}$ from the ion 1 by the McLafferty type rearrangement leading to ion $\mathbf{m}$ is characteristically found in all the compounds (6-9) (Scheme 4). The formation of ion $\mathrm{m}$ from ion 1 is confirmed by the parent ion scan of ion $\mathbf{m}$ (spectrum not shown). Further, an alkene loss from the alkyl group present on nitrogen from both ions $\mathbf{l}$ and $\mathbf{m}$, resulting in ions $\mathbf{p}$ and $\mathbf{n}$, respectively, is observed in Compounds $\mathbf{6}$ and 9.

Other fragment ions that are diagnostically found
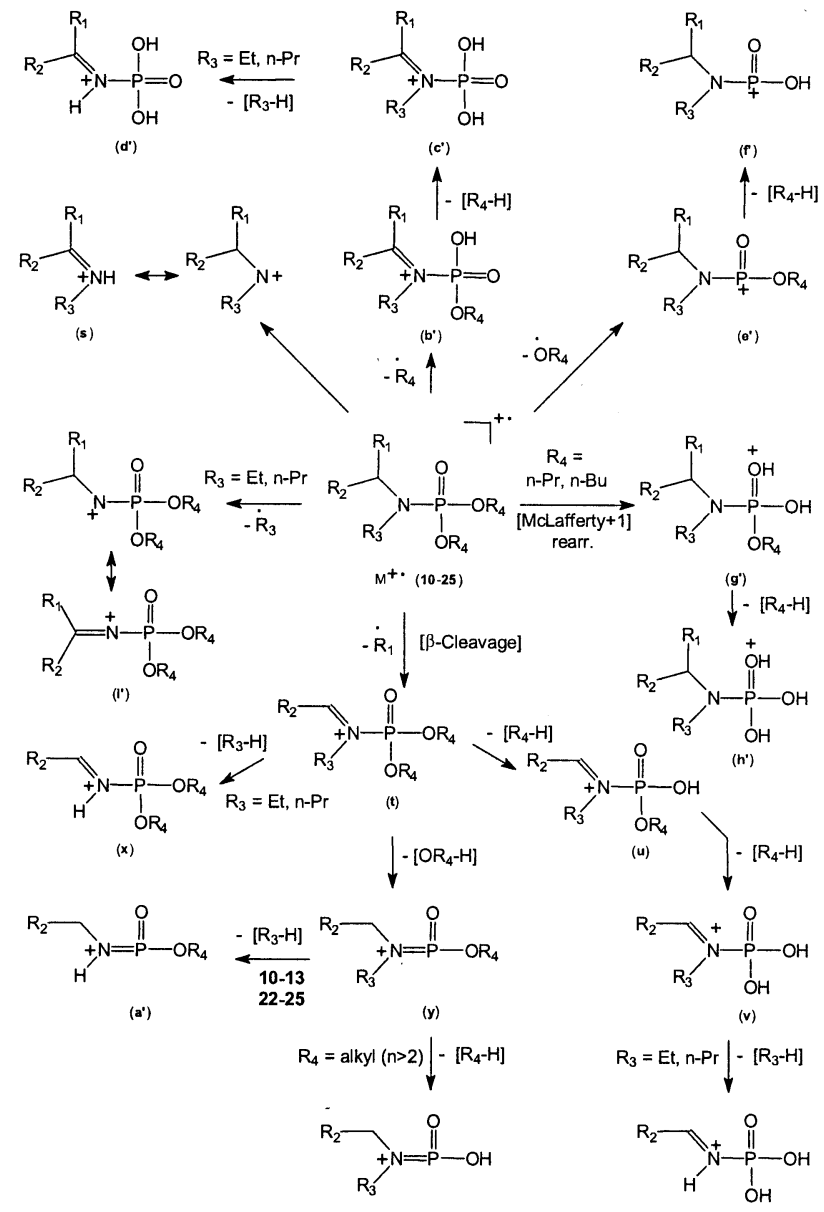

(z)

(w)

Scheme 6 

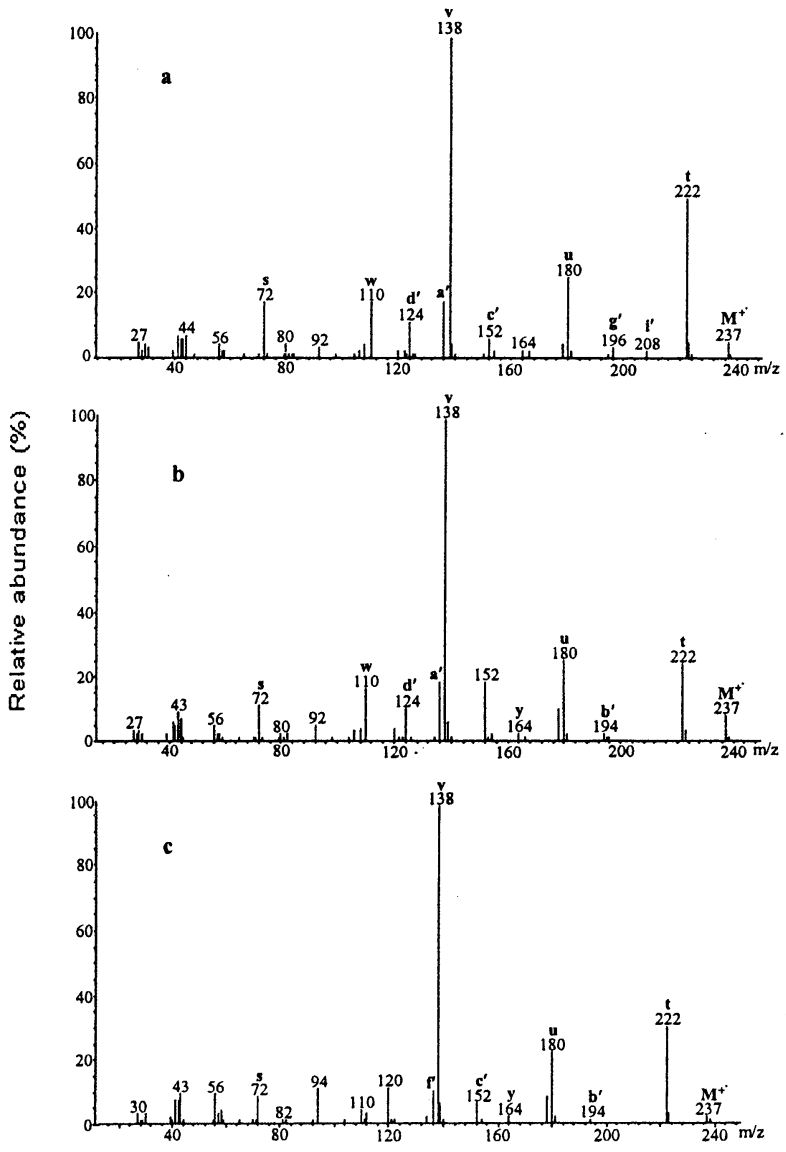

Figure 5. EI mass spectra of (a) Compound 11, (b) Compound 12, and (c) Compound 20.

only in Series 2 compounds are the ions $\mathbf{q}$ and $\mathbf{r}$. The ion $\mathbf{q}$ corresponds to $[\mathrm{M}-\mathrm{R}]^{+}$where $\mathrm{R}$ is the heavier alkyl group present on nitrogen, and the ion $\mathbf{r}$ is formed by the simple elimination of $\mathrm{OCH}_{3}$ radical from the molecular ion. Among the Series 2 compounds, Compound 8 shows a characteristic fragment ion at $\mathrm{m} / \mathrm{z} 134$ (ion o). The parent ion spectrum of ion o shows the ion at $\mathrm{m} / \mathrm{z}$ 166 (ion 1) as the major precursor (Figure 3). The formation of ion $\mathbf{o}$ from ion $\mathbf{l}$ is further confirmed by the CID spectrum of ion 1 . The product ion spectra of ion 1 from 7 and 8 clearly reflect the difference, wherein the ethyl loss is dominant in 7 and $\mathrm{CH}_{3} \mathrm{OH}$ loss is dominant in 8 (Figure 4). The formation of ion $\mathbf{o}$ in Compound 8 may be explained by an initial $\gamma$-hydrogen migration in ion 1 followed by $\mathrm{CH}_{3} \mathrm{OH}$ elimination (Scheme 5).

Such kind of alcohol elimination from $\left[\mathrm{M}-\mathrm{CH}_{3}\right]^{+}$ ion is not observed in other phosphoramidates containing $\mathrm{N}$-isopropyl groups (18-21), instead an alkene loss is observed from the higher alkyl groups present.

\section{O,O-Dialkyl N,N-Dialkyl Phosphoramidates} (Series 3)

Compounds of this series show more fragmentation, but follow a regular pathway. The general fragmenta- tion pattern of this series of compounds (10-25) is presented in Scheme 6 and their EIMS data summarized in Table 3. The EI spectra for Compounds 11, 12 and 20 are given in Figure 5. In general, the fragmentation pattern in Series 3 compounds resembles both Series 1 and Series 2 compounds, depending on the size and nature of alkyl groups present on both nitrogen and oxygen. The simple cleavage of phosphoramide bond is found in all the cases, and the charge is always retained on the nitrogen containing fragment (s) as found in Series 1 compounds. Loss of an alkyl radical from one of the alkyl groups, preferably the higher alkyl chain present on nitrogen by $\beta$-cleavage process leads to fragment ion $\mathbf{t}$, as observed in the case of Series 2 compounds. However, further sequential elimination of alkene from alkyl groups present on oxygen giving rise to the ions $\mathbf{u}$ and $\mathbf{v}$ is observed in all Series 3 compounds (Scheme 6 ). The ion $\mathbf{v}$ is found to be the base peak in all the compounds except in 22. Alkene loss from ions $\mathbf{v}$ and $\mathbf{t}$ involving the other alkyl group present on nitrogen resulting in the formation of ions $\mathbf{w}$ and $x$, respectively, is observed in the case of 10-13 and 22-25. The expulsion of $\mathrm{OC}_{n} \mathrm{H}_{2 n}(n \geq 2)$ moiety from ion $\mathbf{t}$ is also found in all the cases (ion $\mathbf{y}$, Scheme 6) as similarly found in Series 2. But, in some cases the $\mathrm{m} / \mathrm{z}$ value of ion $\mathbf{y}$ is coinciding with other fragment ions. Further, the elimination of an alkene from ion $\mathbf{y}$ involving the alkyl group present either on oxygen or nitrogen (ions $\mathbf{z}$ and $\mathbf{a}^{\prime}$ in Scheme 6) is found in compounds having the alkyl group other than methyl group.

All the Series 3 compounds show $[M-R]^{+}\left(\mathbf{b}^{\prime}\right)$ and $[\mathrm{M}-\mathrm{R} \text {-alkene }]^{+}\left(\mathbf{c}^{\prime}\right)$ ions involving the alkyl groups on oxygen as depicted in the case of Series 1 compounds (Scheme 3). Loss of another alkene from the ion $\mathbf{c}^{\prime}$ giving rise to ion $\mathbf{d}^{\prime}$ can be seen in the case of compounds 10-13 and 22-25. Similarly, elimination of an alkoxy radical from the molecular ion followed by an alkene loss from another alkyl group on oxygen resulting in the ions $\mathbf{e}^{\prime}$ and $\mathbf{f}^{\prime}$ are observed in all the EI spectra of Series-3 compounds, as found in Series 1. The fragment ions resulted by McLafferty rearrangement as found in Series 1 compounds, are not observed in this series of compounds. However, the fragment ions resulting by [McLafferty +1 ] rearrangement (ion $\mathbf{g}^{\prime}$ ) followed by an alkene loss (ion $\mathbf{h}^{\prime}$ ) are observed in the case of $11,13,15,17,19,21$, and 25 . The elimination of an alkyl group (ion $\mathbf{i}^{\prime}$ ), preferably the heavier one present on nitrogen is found in Compounds 10-13 and 22-25, as observed in Series 2 compounds.

\section{Differentiation of Isomeric Compounds}

The isomerism among the studied phosphoramidates (1-25) is exclusively due to size and structure of alkyl groups attached to both oxygen and nitrogen (structural isomers). Table 4 represents Compounds 1-25 listed based on increasing order of their molecular weight and their retention time in gas chromatography. One compound may be isomeric to another in one of three 
Table 4. The isometric compounds among Compounds 1-25 and their GC retention times

\begin{tabular}{|c|c|c|c|c|c|c|}
\hline \multirow[b]{2}{*}{$\begin{array}{l}\text { Mol. } \\
\text { wt. }\end{array}$} & \multirow[b]{2}{*}{$\begin{array}{c}\text { Compound } \\
\text { no. }\end{array}$} & \multirow[b]{2}{*}{$\begin{array}{c}\text { Series } \\
\text { (fragmentation } \\
\text { pattern) }\end{array}$} & \multirow[b]{2}{*}{$\begin{array}{c}\mathrm{RT} \\
(\mathrm{min})\end{array}$} & \multirow[b]{2}{*}{$\begin{array}{c}\text { Total } \\
\text { possible } \\
\text { isomers }\end{array}$} & \multicolumn{2}{|c|}{ Studied isomeric pairs } \\
\hline & & & & & $\begin{array}{l}\text { O-n-Pr } \\
\text { and } \\
\text { O-i-Pr }\end{array}$ & $\begin{array}{l}\mathrm{N}, \mathrm{N} \text {-diethyl } \\
\text { and } \\
\mathrm{N} \text {-i-Pr, N-Me }\end{array}$ \\
\hline 153 & 5 & 2 & 7.17 & - & - & - \\
\hline \multirow[t]{4}{*}{181} & 1 & 1 & 8.94 & 6 & - & $(6,8)$ \\
\hline & 8 & 2 & 9.38 & & & \\
\hline & 6 & 1 & 9.48 & & & \\
\hline & 7 & 2 & 9.72 & & & \\
\hline \multirow[t]{6}{*}{209} & 3 & 1 & 9.57 & 15 & $(2,3)$ & $(10,18)$ \\
\hline & 18 & 3 & 10.85 & & & \\
\hline & 10 & 3 & 10.94 & & & \\
\hline & 14 & 3 & 11.2 & & & \\
\hline & 2 & 1 & 11.52 & & & \\
\hline & 9 & 2 & 11.78 & & & \\
\hline \multirow[t]{8}{*}{237} & 20 & 3 & 11.27 & 28 & $(11,12)$ & $\begin{array}{l}(11,19) \\
(12,20)\end{array}$ \\
\hline & 12 & 3 & 11.38 & & $(15,16)$ & \\
\hline & 16 & 3 & 11.61 & & $(19,20)$ & \\
\hline & 22 & 3 & 12.96 & & & \\
\hline & 19 & 3 & 13.14 & & & \\
\hline & 11 & 3 & 13.32 & & & \\
\hline & 15 & 3 & 13.45 & & & \\
\hline & 4 & 1 & 13.86 & & & \\
\hline \multirow[t]{5}{*}{265} & 24 & 3 & 13.26 & 10 & $(23,24)$ & $(13,21)$ \\
\hline & 23 & 3 & 14.98 & & & \\
\hline & 21 & 3 & 15.28 & & & \\
\hline & 13 & 3 & 15.32 & & & \\
\hline & 17 & 3 & 15.55 & & & \\
\hline \multirow[t]{2}{*}{293} & 25 & 3 & 16.85 & - & - & - \\
\hline & & & total & 59 & 5 & 5 \\
\hline
\end{tabular}

different ways; (1) having difference in the structure of alky group (e.g., n-propyl or isopropyl) attached to nitrogen or oxygen, (2) having a set of alkyl groups present on oxygen in one isomer and on nitrogen in another isomer and vice versa (crossed alkyl groups), and (3) having different size of alkyl groups randomly between nitrogen and oxygen leading to same molecular formulae (mixed alkyl groups). There are four, six, eight, and five compounds with molecular weight of 181, 209, 237 and 265, respectively (Table 4). Statistically, 6, 15, 28, and 10 isomeric pairs (a total of 59) are possible in this group of isomers possessing molecular weight 181, 209, 237, and 265, respectively (Table 4). Among these, 44 isomeric pairs have alkyl groups of different size and structure (mixed or crossed alkyl groups), and hence, can be easily differentiated from one another because their EI fragmentation pattern is totally influenced by the alkyl groups present leading to distinct EI mass spectra. Usually, the isomers having isomeric alkyl groups such as n-propyl or isopropyl, are difficult to distinguish from each other. In the present study, there are few such isomeric pairs (10) that differ by the presence of n-propyl or isopropyl on nitrogen or oxygen. The five isomeric pairs where n-propyl or isopropyl is attached to nitrogen $(7,8 ; 14,18 ; 15,19 ; 16,20$; and 17,21 ) can be easily differentiated by their initial EI fragmentation due $\beta$-cleavage process. The selective loss of ethyl radical from molecular ion is observed in n-propyl containing isomers (7 and 14-17) whereas iso-propyl containing isomers $(\mathbf{8}, \mathbf{1 8}-\mathbf{2 1})$ lose a methyl radical from molecular ion by the initial $\beta$-cleavage process. The difference (14 Da) due to ethyl and methyl radical loss is also reflected between isomers in subsequent fragmentation of $\beta$-cleavage product ion as generalized in Schemes 4 and $\mathbf{6}$.

However, the five isomeric pairs in which one isomer has O,O-di-n-propyl and the other has O,O-diisopropyl show resemblance in their EI spectra. Similarly, another set of five isomeric pairs consisting $\mathrm{N}, \mathrm{N}$ diethyl group or $\mathrm{N}$-isopropyl $\mathrm{N}$-methyl group also result in almost similar spectra. These typical isomeric pairs are discussed below in detail.

\section{O,O-Di-n-Propyl and O,O-Di-Isopropyl Groups Containing Isomers}

The five isomeric pairs which differ in their structure having O,O-di-n-propyl in one isomer and O,O-diisopropyl in another isomer are 2,3; 11,12; 15,16; 19,20; and 23,24 . The fragmentation pattern for major ions in the $\mathrm{O}, \mathrm{O}$-di-n-propyl phosphoramidates is similar to that of the corresponding O,O-di-isopropyl isomer (Figure 5). Though overall spectra of each isomeric pair look 


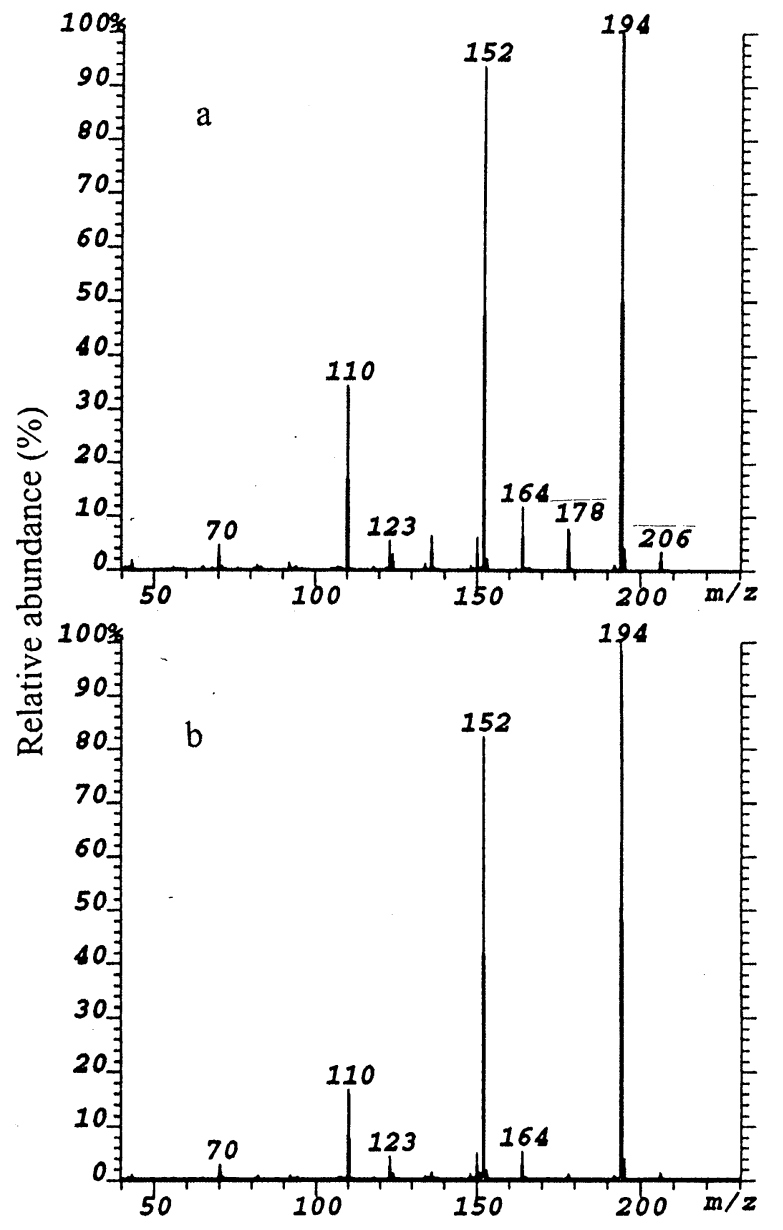

Figure 6. Daughter-ion spectra of the ion at $\mathrm{m} / \mathrm{z} 236$ from (a) Compound 23, (b) Compound 24.

similar, some of the fragment ions are found to be diagnostic of O,O-di-n-propyl or O,O-di-isopropyl groups. In these isomeric compounds, the $\beta$-cleavage ion and fragment ions due to subsequent alkene elimination are dominant in the spectra. In the isomeric compounds $\mathbf{2}$ and $\mathbf{3}$, the fragmentation is centered around $\mathrm{O}, \mathrm{O}-\mathrm{di}$-alkyl part and hence, a large difference in fragmentation due to n-propyl and iso-propyl can be seen. The O,O-di-isopropyl containing Compound 3 shows dominant McLafferty rearrangement process $(\mathrm{m} / \mathrm{z}$ 167), whereas the isomeric O,O-di-n-propyl Compound 2 undergoes [McLafferty +1 ] rearrangement process $(\mathrm{m} / \mathrm{z}$ 168). Similar trend is also observed in subsequent alkene elimination from McLafferty or $[$ McLafferty +1$]$ rearrangement ions, resulting in ions at $m / z 125$ and 126, respectively. The ion at $\mathrm{m} / z 125$ is dominant in $\mathbf{3}$ and in the case of $\mathbf{2}$ the ion $\mathrm{m} / \mathrm{z} 126$ is dominant. In addition, $\left[\mathrm{M}-\mathrm{C}_{3} \mathrm{H}_{7}\right]^{+}$ion is also dominant in $\mathbf{3}$.

In the case of other isomeric pairs $(\mathbf{1 1}, \mathbf{1 2} ; \mathbf{1 5}, \mathbf{1 6} ; \mathbf{1 9}, \mathbf{2 0}$; and 23,24), having higher alkyl groups on nitrogen, the fragmentation is influenced by the $\beta$-cleavage and its posterior ions being other fragment ions of less abundance. The $\beta$-cleavage ion is always found to be dom-

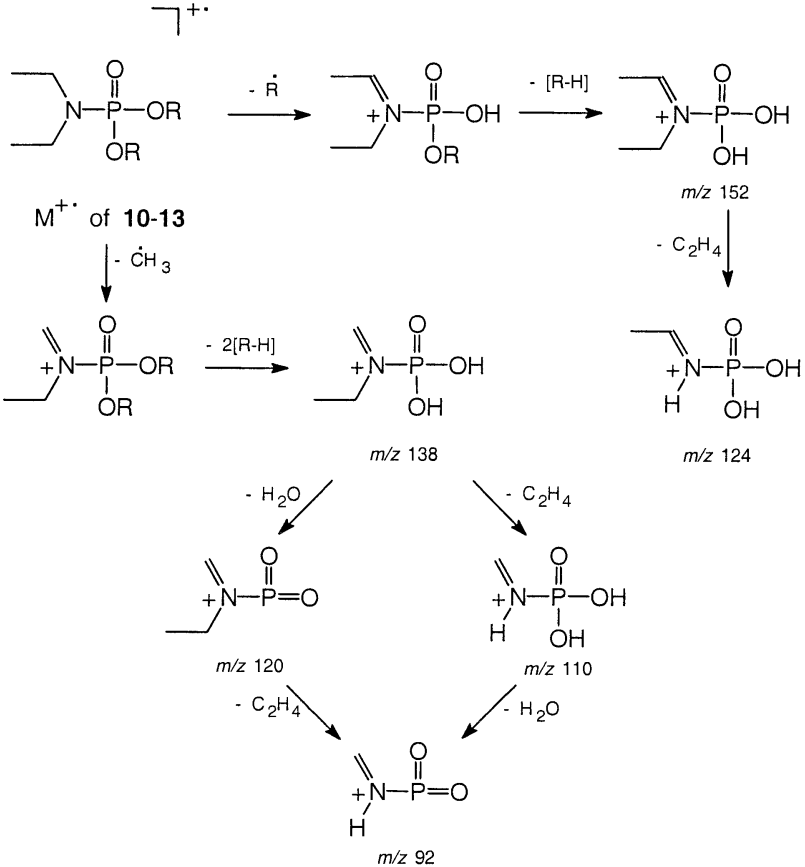

Scheme 7

inant in O,O-di-n-propyl isomer. The McLafferty rearrangemt ion is completely absent in the EI spectra of all these isomers. The [McLafferty +1$]$ rearrangement ion $(\mathrm{m} / \mathrm{z}$ 196) characteristic of O,O-di-n-propyl group is low

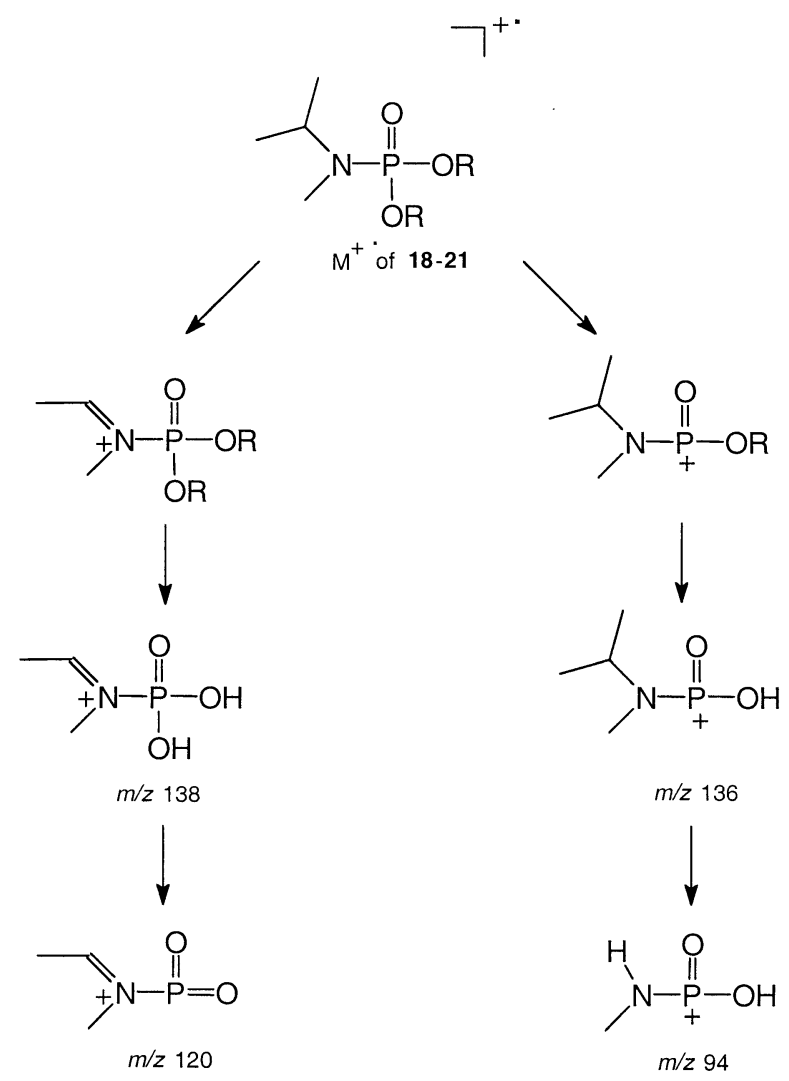

Scheme 8 


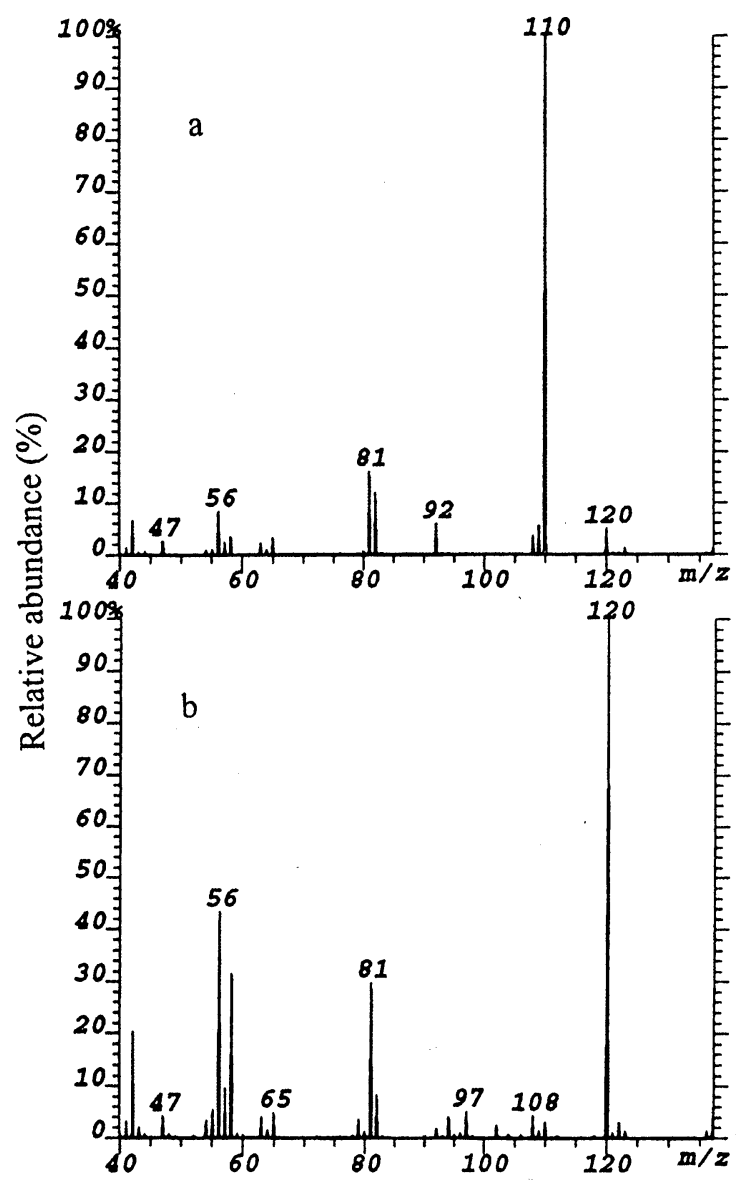

Figure 7. Daughter-ion spectra of the ion at $\mathrm{m} / \mathrm{z} 138$ from (a) Compound 12, (b) Compound 20.

abundant but noticeble in $\mathbf{1 1}$ and $\mathbf{1 5}$, and is absent in their corresponding $\mathrm{O}, \mathrm{O}$-di-isopropyl isomer (12 and 16). The $\left[\mathrm{M}-\mathrm{C}_{3} \mathrm{H}_{7}\right]^{+}$and $\left[\mathrm{M}-\mathrm{C}_{3} \mathrm{H}_{7}-\mathrm{C}_{3} \mathrm{H}_{6}\right]^{+}$ions are invariably dominant in O,O-di-isopropyl isomers $(\mathbf{1 2 , 1 6}$, and 20). The isomeric pair of 23 and 24 contains $\mathrm{n}$ - and iso-propyl groups on the nitrogen and oxygen and show resemblance in their EI spectra and CID spectra of the molecular ions (spectra not shown). The characteristic fragment ions due to n-propyl and isopropyl groups are negligible in the spectra. However, the $\left[\mathrm{M}-\mathrm{C}_{2} \mathrm{H}_{5}-\mathrm{CH}_{3} \mathrm{CH}_{2} \mathrm{CHO}\right]^{+}$ion at $\mathrm{m} / \mathrm{z} 178$ and further $\mathrm{C}_{3} \mathrm{H}_{6}$ loss from ion at $\mathrm{m} / z 178$ resulting in the ion at $m / z 136$ are prominent in $\mathbf{2 3}$. The observed difference in the fragmentation is more prominent in the CID spectra of the $\beta$-cleavage ion, $\left[\mathrm{M}-\mathrm{C}_{2} \mathrm{H}_{5}\right]^{+}$at $\mathrm{m} / z 236$ from 23 and 24 (Figure 6). The $\left[\mathrm{M}-\mathrm{C}_{3} \mathrm{H}_{7}-\mathrm{C}_{3} \mathrm{H}_{6}\right]^{+}$ion at $\mathrm{m} / \mathrm{z} 180$ is relatively abundant in the EI spectrum of $\mathbf{2 4}$.

\section{N,N-Diethyl and N-Isopropyl N-Methyl Groups Containing Isomers}

The five isomeric pairs $(6,8 ; 10,18 ; 11,19 ; 12,20$; and $13,21)$ consisting $\mathrm{N}, \mathrm{N}$-diethyl group or $\mathrm{N}$-isopropyl, $\mathrm{N}$-methyl group show resemblance in their EI mass spectra and the EI mass spectra for $\mathbf{1 2}$ and $\mathbf{2 0}$ are given

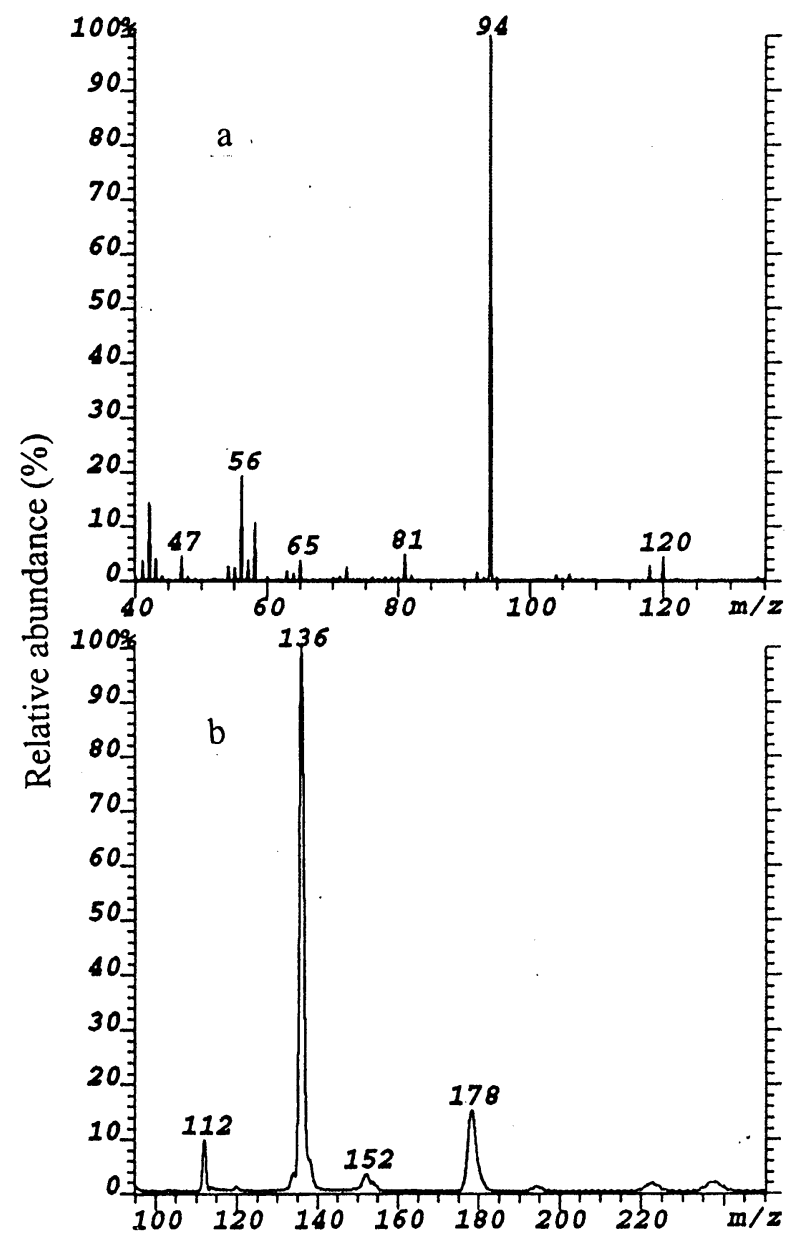

Figure 8. (a) Daughter-ion spectrum of the ion at $\mathrm{m} / \mathrm{z} 136$ from Compound 20, (b) parent ion spectrum of the ion at $\mathrm{m} / \mathrm{z} 94$ from Compound 20.

Figure 5 as an example. The spectral similarity due to methyl radical elimination by $\beta$-cleavage around nitrogen is common in both the isomers. However, clear-cut difference in the low mass region of the spectra is observed in all the compounds, except in $\mathbf{6}$ and $\mathbf{8}$. The $\mathrm{N}, \mathrm{N}$-diethyl isomers (10-13) show specific fragment ions at $\mathrm{m} / \mathrm{z} 124$ and 92, whereas the fragment ions at $\mathrm{m} / \mathrm{z}$ 120 and 94 are diagnostic to $\mathrm{N}$-isopropyl-N-methyl isomers (18-21). The ions at $\mathrm{m} / \mathrm{z} 124$ and 92 prove to be characteristic of $\mathrm{N}, \mathrm{N}$-diethyl group based on metastable ion data as summarized in Scheme 7. The parent ion spectrum of $\mathrm{m} / \mathrm{z} 92$ from 12 show the ion at $\mathrm{m} / \mathrm{z} 138$ and 120 as major precursors, and that of $\mathrm{m} / z 124$ gives $\mathrm{m} / \mathrm{z}$ 152 as the major parent (spectra not shown). Though the fragmentation in $\mathbf{1 0 - 1 3}$ is initiated by the $\beta$-cleavage and centered on alkoxy groups, one of the ethyl groups in the N,N-di-ethyl moiety is intact in the initial fragment ions and lead to ions at $\mathrm{m} / \mathrm{z} 124$ and 92 by the elimination of $\mathrm{C}_{2} \mathrm{H}_{4}$ from the respective parent. Similarly, the predominant ion at $\mathrm{m} / z 120$ in N-isopropyl-Nmethyl isomers (18-21) is due to preferential loss of water from the ion at $\mathrm{m} / \mathrm{z} 138$, as the process of alkene loss as found in $\mathrm{N}, \mathrm{N}$-dimethyl compounds is not pos- 


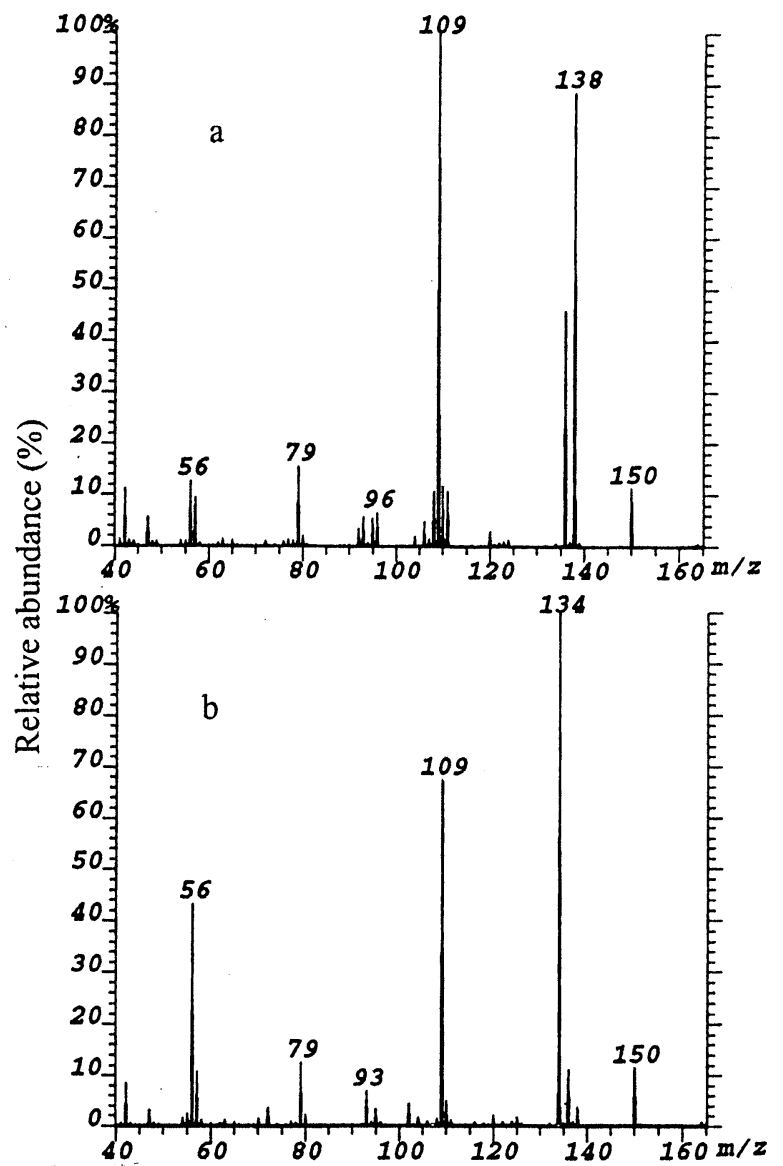

Figure 9. Daughter-ion spectra of the ion at $m / z 166$ from (a) Compound 6, (b) Compound 8.

sible (Scheme 8). The favorable loss of water molecule from the ion at $m / z 138$ in 18-21 is confirmed by the CID spectra of the ion at $\mathrm{m} / \mathrm{z} 138$ of $\mathbf{1 2}$ and $\mathbf{2 0}$, and this process is negligible in $\mathrm{N}, \mathrm{N}$-diethyl isomers (10-13) (Figure 7). The formation of the ion at $\mathrm{m} / \mathrm{z} 94$ diagnostic to $\mathrm{N}$-isopropyl-N-methyl isomers is explained in Scheme 8. The parent ion spectrum of the ion at $\mathrm{m} / \mathrm{z} 94$ from 20 clearly points out the ion at $m / z 136$ as the major precursor, apart from other minor precursors at $\mathrm{m} / \mathrm{z} 178$ and 112 and the CID spectrum of the ion at $\mathrm{m} / \mathrm{z} 136$ (Figure 8) also supports this pathway.

The isomeric Compounds $\mathbf{6}$ and $\mathbf{8}$ do not show the above characteristic peaks of $\mathrm{N}, \mathrm{N}$-diethyl and $\mathrm{N}$-isopropyl, N-methyl groups, because the alkyl groups attached to oxygen are methyl groups. The $\beta$ - cleavage process in both the isomers leads to the ion at $\mathrm{m} / \mathrm{z} 166$, but the structure of this ion is proved to be different from CID experiments (Figure 9). The removal of $\mathrm{C}_{2} \mathrm{H}_{4}$, distinctive of ethyl group, is selectively found in the dissociation of $m / z 166$ from 6, whereas the elimination of $\mathrm{CH}_{3} \mathrm{OH}$ is characteristic for Compound $\mathbf{8}$ as depicted in Scheme 5. In addition, expulsion of $\mathrm{CH}_{2} \mathrm{O}$ from $\mathrm{m} / \mathrm{z}$ 166 via McLafferty type rearrangement is favorable in Compound 6. Similar trend is observed in their respective EI mass spectra. Direct $\mathrm{C}_{2} \mathrm{H}_{5}$ radical elimination from molecular ion is only possible in 6 , and the [M $\left.\mathrm{C}_{2} \mathrm{H}_{5}\right]^{+}$ion is observed in the EI spectrum at $m / z 152$.

\section{Conclusions}

A series of O,O-dialkyl, N,N-dimethyl (Series 1), O,Odimethyl, N,N-dialkyl (Series 2) and O,O-dialkyl, N,Ndialkyl phosphoramidates (Series 3), where alkyl = methyl, ethyl, n-propyl, iso-propyl, and n-butyl, have been studied extensively under GC/EIMS conditions. The general fragmentation pattern arrived for these compounds as supported by metastable ion data clearly reveals that Series 1 and 2 compounds show distinctive fragmentation pattern. The Series 3 compounds produce fragment ions of both Series 1 and 2 influenced by the nature of alkyl groups attached to nitrogen/oxygen. The simple cleavage of $\mathrm{P}-\mathrm{N}$ bond is found to be more favorable than that of $\mathrm{P}-\mathrm{O}$ bond. The charge is retained extensively on nitrogen containing fragment if the oxygen had larger alkyl group (> methyl, Series 1 and 3 ), or on both the fragments if oxygen contained the methyl group (Series 2). In the case of Series 1 compounds the fragmentation is mostly centered on $\mathrm{O}, \mathrm{O}-$ dialkyl part, leading to fragment ions corresponding to $[\mathrm{M}-\mathrm{R}]^{+},[\mathrm{M}-\mathrm{OR}]^{+}$, McLafferty, and [McLafferty + 1] rearrangement ions and subsequent alkene elimination from these fragment ions, depending on the size and structure of alkyl groups linked to oxygen. If higher alkyl groups $\left(>\mathrm{CH}_{3}\right)$ are attached to nitrogen (Series 2 and 3), the fragmentation is initiated on nitrogen by $\beta$-cleavage process. Then the fragmentation propagates by sequential alkene elimination if higher alkyl group is either on oxygen (Series 3 ) or on nitrogen (Series 2). The fragment ions resulting from the direct involvement of $\mathrm{O}, \mathrm{O}$-dialkyl part are of less abundance. Expulsion of $\mathrm{OC}_{n} \mathrm{H}_{2 \mathrm{n}}$ moiety from $\beta$-cleavage product ion by McLafferty type rearrangement is also observed in Series 2 and 3 compounds. From the general fragmentation pattern observed for the studied compounds (1-25), it is very easy to assign the structure for each compound due to characteristic fragmentation influenced not only by the size and structure of alkyl groups but also by the site of attachment of alkyl group. Similarly, even the isomeric compounds could be easily differentiated, as the EIMS of one isomer is distinctive to another isomer. However, the isomers that differ by the presence of n-propyl or isopropyl on oxygen and due to $\mathrm{N}, \mathrm{N}$-dietyl or N-isopropyl, N-methyl on nitrogen typically show resemblance in their EI spectra. But, it is clearly shown that these isomers could be distinguished unambiguously after careful analysis of the characteristic ions of low abundance and the fragment ions at low mass region in their respective EIMS.

\section{Acknowledgments}

The authors are grateful to the Director, IICT, for his encouragement and financial support to one of the authors (TJR). 


\section{References}

1. Budiansky, S. United Nations Accuses Iraq of Military Use. Nature 1984, 308, 483.

2. Sass, S.; Fisher, T. L. Chemical Ionization and Electron Impact Mass Spectrometry of Some Organophosphonate Compounds. Org. Mass Spectrom. 1979, 14, 257-264.

3. Wils, E. R. J. Mass Spectral Data of Precursors of Chemical Warfare Agents. Fresenius J. Anal. Chem. 1990, 338, $22-27$.

4. Gillis, R. G.; Occoclowitz, J. L. The Mass Spectrometry of Phosphorous Compounds. In Analytical Chemistry of Phosphorus Compounds, Halman, M., Ed.; Wiley Interscience: New York, 1972; pp 295-331.

5. D'Agostino, P. A.; Provost, L. R. Determination of Chemical Warfare Agents, Their Hydrolysis Products, and Related Compounds in Soil. J. Chromatogr. 1992, 589, 287-294.

6. D'Agostino, P. A.; Provost, L. R.; Looye, K. M. Identification of Tabun Impurities by Combined Capillary Column Gas Chromatography-Mass Spectrometry. J. Chromatogr. 1989, 465, 271-283.

7. D'Agostino, P. A.; Hansen, A. S.; Lockwood, P. A.; Provost, L. R. Capillary Column Gas Chromatography-Mass Spectrometry of Tabun. J. Chromatogr. 1985, 347, 257-266.

8. D'Agostino, P. A.; Provost, L. R.; Visentini, J. Analysis of O-Ethyl S-[2-(Diisopropylamino)Ethyl] Methyl Phosphonothiolate (VX) by Capillary Column Gas ChromatographyMass Spectrometry. J. Chromatogr. 1987, 402, 221-232.

9. D’Agostino, P. A.; Provost, L. R. Mass Spectrometric Identifications of Products Formed During Degradation of Ethyl Dimethyl-Phosphoramidocyanidate (Tabun). J. Chromatogr. 1992, 598, 89-95.

10. Davidowitz, B.; Modro, T. A. Phosphoric Amides 7-Mass Spectrometry of Phosphoric Amido Esters: Fragmentation Patterns and Migratory Aptitudes. Org. Mass Spectrom. 1984, 19, 128-134.
11. Vijaya Saradhi, U. V. R.; Suryanarayana, M. V. S.; Gupta, A. K.; Semwal, R. P.; Jayaram, B. Studies on the Response Mechanism of Thermionic Detection to Organophosphorus Compounds. J. Chromatogr. A 2001, 911, 63-73.

12. Kolb, B.; Bischoff, J. New Design of a Thermionic Nitrogen and Phosphorous Detector for GC (Gas-Chromatography). J. Chromatogr. Sci. 1974, 12, 625.

13. Hooijschuur, E. W. J.; Kientz, C. E.; Brinkman, U. A. T. Analytical Separation Techniques for the Determination of Chemical Warfare Agents. J. Chromatogr. A 2002, 982, 177-200.

14. Kientz, C. E. Chromatography and Mass Spectrometry of Chemical Warfare Agents, Toxins, and Related Compounds: State of the Art and Future Prospects. J. Chromatogr. A 1998, 814, 1-23.

15. Reddy, T. J.; Mirza, S. P.; Vijaya Saradhi, U. V. R.; Rao, V. J.; Vairamani, M. Mass Spectral Studies of N,N-Dialkylaminoethanols. Rapid Commun. Mass Spectrom. 2003, 17, 746-752.

16. McIvor, R. A.; McCarthy, G. D.; Grant, G. A. Preparation and Toxicity of Some Alkyl Thiopyrophosphates. Can. J. Chem. 1956, 34, 1819-1832.

17. Zwierzak, A. Phase-Transfer-Catalyzed Phosphorylation of Amines in an Aqueous System. Synthesis 1975, 507-509.

18. Baumgarten, H. E.; Setterquist, R. A. Reaction of Amines IV-Pyrolysis of Dialkyl N-Alkyl Phosphoramidates. J. Am. Chem. Soc. 1959, 81, 2132-2136.

19. Kingeston, D. G. I.; Bursey, J. T.; Bursey, M. M. Intramolecular Hydrogen Transfer in Mass Spectra, II. The McLafferty Rearrangement and Related Reactions. Chem. Rev. 1974, 74, 215242.

20. Weisz, A.; Mandelbaum, A.; Blum, W.; Domon, B.; Muller, D.; Richter, W. J.; Schabanowitz, J.; Funt, D. F. Applications of Low Energy CID in the Determination of Structures of [MHalogen $]^{+}$Ion Obtained from Diethyl Halosuccinates Under Electron Impact. Org. Mass Spectrom. 1987, 22, 61-63. 